\title{
Can Inoculation Withstand Multiple Attacks?
}

\section{An Examination of the Effectiveness \\ of the Inoculation Strategy Compared \\ to the Supportive and Restoration Strategies}

\author{
Bobi Ivanov ${ }^{1}$ \\ University of Kentucky \\ Michael Pfau \\ University of Oklahoma \\ Kimberly A. Parker \\ Bellarmine University
}

\begin{abstract}
This investigation introduced multiple competitive attacks in order to assess the effectiveness of inoculation treatments in protecting established attitudes in a natural setting. A four-phase experiment was conducted involving 433 participants. The results revealed that the effectiveness of refutational inoculation messages dissipated some in the face of an additional attack. Still, refutational inoculation messages proved to be more effective than supportive, restoration, and control (no message) conditions in protecting established attitudes in the face of multiple attacks. The content of an additional attack (the same as the first attack or different) did not affect the capacity of inoculation refutational messages to confer resistance to competitive attacks.
\end{abstract}

Keywords: inoculation; resistance; multiple attacks

$\mathrm{T}$

o improve consumer information, the Federal Trade Commission (FTC) encouraged companies in advertisements to refer to their competitors by their actual or brand names rather than as "Company X" or "Brand X" (Belch \& Belch, 2007; Boddewyn \& Marton, 1978; Dougherty, 1973; Ulanoff, 1975). As a result, use of comparative advertising has rapidly increased (Pride, Lamb, \& Pletcher, 1979) and now represents nearly half of all ads (see Belch \& Belch, 2007; Levy, 1987; Pfau, 1992). Research shows comparative ads to be effective in tarnishing the images of competitors and enhancing the images of marketers (Atkin, 1984; Droge, 1989; Pfau, 1991).

To combat comparative ads, marketers have a limited set of strategies at their disposal (Pfau, 1992). They can use a comparative strategy of their own, which helps tarnish the image of their competitors but does little in restoring the image of their 
brand. Alternatively, they can employ refutation, or response-advertising, as an explicit rebuttal of the competitor's attack (Pfau, 1992). However, both of these strategies are post hoc and do little to protect a brand's image against future attacks (see Pfau, 1992).

The supportive (advertising) strategy is administered prior to a potential attack and provides reasons for holding attitudes, thereby bolstering those attitudes. This strategy's success depends, in large part, on instilling confidence in current attitudes, which undercuts pressure to change (McGuire, 1961a). An alternative strategy is based on inoculation theory, which posits two mechanisms as responsible for resistance to persuasion: threat and refutational preemption (McGuire, 1961a). The threat element generates acknowledgement that an attitude is vulnerable, which induces motivation for people to strengthen the attitude. The defense building increases effective counteraruging, which, in turn, bolsters the attitude (McGuire, 1961a).

Previous studies have found inoculation theory to be an effective preemptive strategy in conferring resistance to comparative advertising attacks directed at a product's brand name (Pfau, 1992) or Country-of-Origin (COO) image (Ivanov, Pfau, \& Parker, 2007). However, the endurance of inoculation has never been examined in the face of repetitive attacks. Attack messages have been manipulated in the past but mainly focusing on message content (e.g., Burgoon, Cohen, Miller, \& Montgomery, 1995; Lee \& Pfau, 1997; Pfau, Kenski, Nitz, \& Sorenson, 1990) or message timing (e.g., McGuire, 1961a, 1966; McGuire \& Papageorgis, 1961; Pfau \& Burgoon, 1988; Pryor \& Steinfatt, 1978) but not the number of attack messages encountered. This omission is puzzling, since it is reasonable to expect that competitors would use multiple attack messages in order to achieve their goals and, therefore, individuals will encounter multiple attacks (Pfau et al., 2001). Hence, the goal of this investigation is to determine the effectiveness of inoculation against multiple attacks. Can inoculation effects withstand multiple attacks? And, even if they do, would attitudes strengthen, weaken, or remain unchanged with each subsequent attack? Furthermore, does the nature of the second attack (featuring same or different content as the first attack) moderate the effectiveness of the inoculation defenses? Finally, in the face of multiple attacks, how does inoculation defense fare compared to other defense strategies? The focus of this investigation is to provide answers to these questions, which are important to inoculation's utility and yet have not previously been addressed.

\section{Inoculation and Multiple Attacks}

\section{Number of Competitor Attacks and Inoculation}

The inoculation literature offers two possible scenarios which may illuminate the possible relationship between the inoculation treatment, the initial attack, and additional attacks. To better understand the inoculation process, two issues need to be 
examined: delay and decay (Compton \& Pfau, 2005). Delay refers to the time needed for an individual to generate counterarguments necessary for protecting attitudes, while decay refers to the persistence of inoculation treatments over time (Compton \& Pfau, 2005).

Previous research has shown that inoculation treatments lose effectiveness over time (McGuire, 1962; Pfau, 1997; Pfau et al., 1990; Pryor \& Steinfatt, 1978). This outcome may be attributed to the individual's loss of motivation to continue to generate additional defenses over time (Compton \& Pfau, 2005; McGuire, 1962). Insko (1967) stated that "induced motivation" to accumulate "belief-bolstering material" will decline over time following "the ordinary forgetting curve" (p. 316). Consequently, as a result of time induced motivation decay, the individual should be less able to protect his or her attitude after every subsequent attack. Based on this rationale, inoculation treatments should be less effective with each subsequent attack. Hence, it can be hypothesized that each additional attack should weaken inoculation's effects.

While time may limit the effectiveness of inoculation with each subsequent attack, the use of booster sessions or reinforcements may extend or even enhance its effectiveness. Booster messages, or double defenses as referred to by McGuire (1961b), find their basis in the medical analogy. Just as medical booster shots should increase the individual's resistance to diseases, reinforcements, or message boosters, should strengthen the individual's ability to defend his or her attitude. So, what is the potential of inoculation booster messages in the face of multiple attacks?

After receiving an inoculation treatment, individuals are motivated to strengthen attitudes by generating counterarguing output, which can be used to deflect attacks. Counterarguing refutes the content of potential attack messages, thus strengthening attitudes. Consequently, the counterarguing activity may itself serve as a booster session, as individuals actively refute arguments contrary to attitudes. In addition, arguments presented in an attack message may motivate the individual to further shore up attitudes, rendering them more resistant to additional attacks. Following this rationale, attitudes may strengthen with every subsequent attack; hence, it could be hypothesized that the effectiveness of inoculation increases with each subsequent attack.

However, the literature on the effectiveness of booster sessions in resistance is equivocal. Tannenbaum, Macauley, and Norris' (1966) found booster messages enhanced resistance, but results fell just short of statistical significance. McGuire (1961b) found booster messages enhanced the individual's ability to counterargue but only in situations in which the inoculation message's content matched the content of both the booster and attack messages. Pfau et al. (2004) found reinforcements sustained the level of counterarguing output in individuals over a longer period of time but failed to enhance resistance. Other studies have also found the success of booster sessions to be limited (Pfau, 1992, 1997; Pfau \& Van Bockern, 1994); however, Pfau et al. speculated that the equivocal nature of these findings may be attributed 
to researchers' failure to discover the optimal timing for administration of booster messages, rather than any inherent limitation of booster messages. More important, all studies employing booster sessions administered boosters after the inoculation treatment and before the attack. When the booster messages are introduced before the attack, the individual may still have some reservations about whether an attack may occur and/or may be unprepared for its severity. As a result, people may not put forth sufficient effort to strengthen attitudes. Once the individual has faced an attack, he or she can assess both the likelihood and the severity of the attack, thus becoming more vested and motivated to strengthen attitudes. Consequently, after every subsequent attack, an individual may have greater ability, more practice, and better material to defend attitudes.

Based on the rationales outlined in this investigation, the effects of message decay and booster sessions (message reinforcements) offer two opposing expectations about the effectiveness of inoculation strategy when faced with multiple attacks. The effect of message decay should lessen the effectiveness of inoculation after each subsequent attack, whereas the effect of booster messages may enhance the effectiveness of inoculation. Hence, these opposing factors may offset each other, thus sustaining the effectiveness of inoculation in the face of multiple attacks. However, one of these factors may exert more influence, thereby lessening or enhancing the effectiveness of inoculation.

Do multiple attacks have any impact on effectiveness of inoculation? Would inoculation prove to be robust if used before multiple attacks? Would additional competitor attacks provide more motivation to further bolster attitude defenses, or would multiple attacks, combined with time delay and subsequent message and motivation decay, weaken the individual's defenses? Since multiple attacks have not been introduced in prior inoculation research, there is no empirical evidence about how multiple attacks, in contrast to single attacks, affect receiver's attitudes. In addition, theory suggests conflicting expectations. Therefore, this investigation posits the following research question:

Research Question 1: Does the capacity of refutational inoculation messages to confer resistance to the influence of comparative advertising messages on behalf of competitors increase, decrease, or remain unchanged in the face of more than one attack?

\section{Nature of Second Attack and Inoculation}

Competitors are unlikely to use only a single attack in an attempt to influence consumer attitudes. Typically, organizations employ a whole set of advertisements attacking a perceived weakness or derogating a perceived strength of competitors and their products (e.g., Arndorfer, 2004, 2005; Atkinson, 2007; Carter, 2005; MacArthur, 2007; Snyder Bulik, 2007; Sorescu \& Gelb, 2000). Organizations are likely to use multiple attacks in their campaigns relying either on a consistent attack message or a set of different attack messages as variations on the same theme (e.g., 
Arndorfer, 2004, 2005; Atkinson, 2007; Carter, 2005; MacArthur, 2007; Snyder Bulik, 2007; Sorescu \& Gelb, 2000). This raises the question as to whether inoculation would be better able to confer resistance to competitors' attacks when facing the same message in each attack or a barrage of different messages in each attack? An examination of McGuire's two different types of inoculation defenses may provide an answer to this question.

McGuire compared the effectiveness of inoculation defenses based on the message content presented in inoculation treatments and subsequent attacks. In refutational same inoculation treatments, attack messages were based on the same content previously refuted in the preemptive inoculation treatments. In the refutational different inoculation treatments, attack messages did not match, or only partially matched, the content refuted in preemptive inoculation treatments. The results indicated that inoculation worked equally well in both cases (Lee \& Pfau, 1997; McGuire, 1961a, 1962, 1964; McGuire \& Papageorgis, 1961; Papageorgis \& McGuire, 1961; Pfau, 1992; Pfau \& Burgoon, 1988; Pfau et al., 2001, 2004, 2005). With refutational same inoculation messages, the effectiveness of inoculation can be attributed, partially or completely, to the content of the message, since the content provides the necessary material to refute the attacking messages. With refutational different inoculation messages, the content is not responsible for inoculation's impact since the content contained in the inoculation message is different from the content contained in the subsequent attack. Thus, inoculation's effectiveness cannot be derived from the content but rather must stem from the motivation to bolster threatened attitudes (McGuire, 1962, 1964). In finding that inoculation works with both same and different inoculation messages, McGuire was able to document that inoculation's success does not rest on the message content but instead flows from the induced motivation for individuals to bolster their attitudes through counterarguing practice. Research documents that inoculation is equally robust when there is a match or mismatch in the content of the inoculation and subsequent attack messages. A recent meta-analysis, featuring 39 inoculation studies, found no statistically significant differences in the relative effectiveness of refutational same and different inoculation messages (Banas $\&$ Rains, 2008). Thus, the content of the attack message, whether same or different from the one used in the inoculation treatment, should not influence its effectiveness. Consequently, this investigation posits the following:

Hypothesis 1: For people who receive a refutational inoculation treatment, refutational inoculation confers equal resistance to the influences of comparative advertising messages on behalf of competitors regardless of the content of the second attack (same as the first attack or different from the first attack).

\section{Types of Defenses and Multiple Attacks}

Previous research on inoculation has documented superior effectiveness of inoculation compared to other strategies (Ivanov et al., 2007; McGuire, 1961a). This 
investigation focuses on the effectiveness of inoculation versus supportive and restoration strategies in a multiple attacks setting. Thus far, the effectiveness of the inoculation strategy has not been investigated in this context; hence, its robustness in protecting consumer attitudes, as compared to other strategies, is unknown. In the absence of theoretical and empirical evidence, this investigation posits the following research question:

Research Question 2: How effective are various defensive approaches (no message treatment, supportive treatment, refutational treatment, and restoration treatment) in the face of a second attack in conferring resistance to the influence of comparative advertising messages?

\section{Method}

This investigation employed a 4 (product type/country conditions: cars made in Japan or the United States and television sets made in Japan or the United States) $\times$ 4 (experimental message condition: refutational, supportive, restoration, and control) $\times 2$ (second attack message compared to first: same message and different message) between-subjects factorial design.

\section{Product Type and COO Image}

To test the robustness of inoculation against multiple comparative attacks, the investigators selected to protect the positive product type/country image association or $\mathrm{COO}$ effect, which can be defined "as the impact which generalizations and perceptions about a country have on a person's evaluation of the country's products and/ or brands" (Lampert \& Jaffe, 1996, p. 27). This concept affects the perceptions consumers hold about quality of products (Chao, 1993; Cordell, 1991; Mohamad et al., 2000; Roth \& Romeo, 1992). As a heuristic cue, and not necessarily factual one, the COO image is vulnerable to competitive attacks (Arndorfer, 2005; Mitchell, 2004; Morello, 1992); thus, it represents an appropriate vehicle to test different strategies aimed at protecting existing attitudes (i.e., the positive $\mathrm{COO}$ image). To this end, based on a 113 participant pretest sample, two customer products (cars and television sets; see Lampert \& Jaffe, 1998) and two countries (the United States and Japan) were selected for the main study.

\section{Independent Variables: Product Type/Country Conditions, Experimental Materials, and Attack Messages}

Product type/country conditions. The four product type/country conditions were included in the analysis in order to control for possible product type and/or countryspecific effects on the dependent variables. 
Experimental treatments. The study employed a total of 36 messages, 9 for each product type/country association. For each product type/country match, three inoculation (refutational), three supportive, and three restoration messages were designed. Each of these message groups consisted of one affective, one cognitive, and one combined (both affective and cognitive) message. Since 2001, inoculation research has used some combination of cognitive and affective inoculation messages; therefore, this was the mix employed in the current investigation (see Ivanov, Pfau, \& Parker, 2009; Pfau et al., 2001, 2003, 2004, 2005). ${ }^{2}$

Each of the treatment messages began with a paragraph intended to activate the threat level of the receiver. Threat is an integral element of the inoculation construct (McGuire, 1964); hence, each treatment message began with threat activation, with exception of the messages used in the restoration, supportive, and control conditions. In the case of restoration, an attack has already occurred, thus rendering the threat real. In the case of supportive messages, threatening information was not introduced as the effort was placed on bolstering the current attitudes. Also, threat was not manipulated in the control condition as no treatment messages were presented in this condition.

The first paragraph in the supportive messages further reinforced the strength of the attitude, as well as reaffirmed the advantages of owning the product coming from the specific country. The first paragraph in the restoration messages revisited the attacks already faced and then proceeded to the next two paragraphs aimed at restoring the attitude.

The second and third paragraphs offered claims intended to bolster the attitudes at hand (supportive messages) or claims intended to support the positions contrary to existing attitudes and then refuted each of those claims (restoration and inoculation refutational messages). The message claims employed affective, cognitive, or combined (both affective and cognitive) content. Traditionally, affect has been operationalized as message claims that employ affective content based on anecdotes and personal experiences written in affect-laden language and opinion statements (Lee \& Pfau, 1997, Pfau et al., 2001, 2003, 2004, 2005). Cognition was operationalized as message claims that employ objective and neutral content based on statistics, verifiable evidence, and research findings (Lee \& Pfau, 1997; Pfau et al., 2001, $2003,2004,2005)$. The current investigation, in addition to text used in previous studies, used images to deliver the messages (e.g., Nabi, 2003). For affective messages in the inoculation condition, an example of the image used in the Japanesemade television sets condition is a picture of a television set in the forefront featuring a blank screen that gives out a clear impression of a broken television set being kicked by a person in frustration. On the picture itself, the words "Foolish! Foolish! Foolish!" appear. The caption on the side of the messages reads, "You thought Japanese made television sets were good quality! I bet you feel foolish now!" This picture is portrayed in a form of an advertisement used by competitors to tarnish the positive COO image held by consumers - in this particular example, television sets 
made in Japan. In contrast, the affective message in the supportive condition features the same person leisurely relaxing in front of the television set with clear picture. On the picture itself, the words "Japanese TVs. The best buy ever!" appear. The caption on the side of the picture states, "Japanese made TVs have good quality! I bet you already knew that!"

The cognitive messages were constructed in a similar manner by using not only text but also images to ensure equivalence between the affective and cognitive messages. For example, graphs providing statistical evidence were used as images in the cognitive messages by showing JD Power and Associates', a market research firm, longitudinal quality ratings of television sets by country of origin (e.g., Kardes, 2001). A brief look at the cognitive resources models of how information is processed, stored, and retrieved would indicate that processing both images and text may consume more resources than processing only images or text (Mazzocco, 2000; Mazzocco \& Brock, 2006). Thus, to ensure equivalence, both images and text were used to construct the affective and cognitive messages. The combined messages employed a combination of affective and cognitive content.

To further avoid the message outcome from being influenced by language or message variables (Burgoon et al., 1978), this investigation used the Becker, Bavelas, and Braden's (1961) Index of Contingency, which measures the reconstructability of sentences or readability. The purpose of this index is to ensure equivalence in writing style across messages by taking into consideration the total number of nouns and words of each message. Messages receiving similar index scores indicate equivalence. The index scores for the messages ranged from 9.1 to 11.5, indicating relative equivalence.

Attack messages. This investigation tested 8 attack messages, 2 for each product type/country association. Because this investigation attempted to measure the influence of multiple attacks on initial attitudes following inoculation or preceding restoration, for each product type/country association, two attack messages were designed. Manipulation of the attack messages consisted of introducing same and different attack message at two different times following inoculation or preceding restoration in Phase 3 and after restoration in Phase 4.

The content of the attack message was both cognitive and affective, constructed in an equivalent manner to the inoculation, supportive, and restoration messages previously discussed. To ensure equivalence of message wording and readability, the Index of Contingency (Becker et al., 1961) for measuring readability was once again employed. The index scores for the messages ranged from 9.6 to 11.4 indicating relevant equivalence.

\section{Participants and Procedures}

Students $(N=433)$ enrolled in business courses at a large Midwestern university served as participants in this investigation. A number of researchers argue that the 
practice of using students as surrogates in COO studies does not yield substantially different results as compared to using adults (Hawkins, Albaum, \& Best, 1977; Johansson, 1992; Liefeld, 1992; Yavas, 1994).

Phase 1 lasted about 2 weeks. During this phase, participants indicated their attitudes toward the two product types and country images associated with the study. Those participants who indicated positive attitudes toward the $\mathrm{COO}$ on both product types were randomly assigned to one of the two product type conditions. If participants indicated negative or neutral attitudes toward the countries representing both product types, then these participants were excluded from the remainder of the study. The general attitude (i.e., COO image) was assessed in this phase, thus providing benchmarks of the $\mathrm{COO}$ image in regard to the product. In this phase, the $\mathrm{COO}$ importance as a decision-making tool and the initial involvement level with the product type were tested, as they served as covariates in the investigation.

Phase 2 also lasted 2 weeks and commenced in the week immediately following Phase 1. During Phase 2, some participants received a preemptive message (refutational or supportive), whereas others did not (restoration or control). In this phase, threat-manipulation checks were performed to assess the effectiveness of the threat component of inoculation messages.

Phase 3 commenced 2 weeks following Phase 2. During this phase, all of the participants including those in the restoration and control groups received a counterattitudinal attack. After reading the message, participants in the restoration group received a message aimed at rebuilding the damaged $\mathrm{COO}$ image. In addition, counterarguing output, the general attitude (i.e., COO image), and the attitude towards the counterattitudinal attacks were assessed in this phase.

Phase 4 commenced 2 weeks following Phase 3 . The final phase included the second attack message. Some participants received the same message from Phase 3, whereas others received a different message. In addition, once again participants' ability to counterargue was assessed using the check-off recognition procedure. The general attitude (i.e., COO image) and the attitude toward the counterattitudinal attacks were assessed.

\section{Covariates}

Initial (Phase 1) attitude toward the COO image. To control for possible effects of the initial attitude toward the $\mathrm{COO}$ image, this investigation used a four-item, 7-point (where $1=$ most negative and $7=$ most positive) semantic differential scale with the following bipolar adjectives: negative/positive, dislike/like, bad/good, and undesirable/desirable. The reliability of all measures was assessed using Cronbach's alpha. Reliability of the initial attitude measure was .96.

Involvement. This variable was used as a covariate to test for product involvement on behalf of the participants. For this purpose, Zaichkowsky's (1985) PII scale was 
used. The items composing the simplified scale include the bipolar adjectives: unimportant/important, irrelevant/relevant, nonessential/essential, of no concern/of concern to me, does not matter/matters to me, useless/useful, and trivial/fundamental. The reliability was .96 .

COO Importance. $\mathrm{COO}$ importance was also designated as a covariate; this variable indicates the importance of the country image in the decision-making process of consumers. $\mathrm{COO}$ importance was assessed once again using the abbreviated version of Zaichkowsky's (1985) PII scale. The level of reliability was .96.

\section{Manipulation Check Variables: Threat}

The scale items used in this investigation have been successfully used in numerous inoculation studies (Pfau, 1992; Pfau \& Burgoon, 1988; Pfau et al., 2005) and include the following bipolar adjectives: nonthreatening/threatening, not harmful/harmful, not dangerous/dangerous, not risky/risky, calm/anxious, and not scary/scary. The reliability of the threat measure was .95. A manipulation check conducted in Phase 2 confirmed that refutational inoculation messages generate significantly greater levels of threat compared to supportive messages, $F(3,341)=37.52, p<.01, \eta^{2}=.25$.

\section{Dependent Variables}

Attitude toward the COO image. To test the general attitude, participants were asked to indicate their overall impressions of the object (e.g., Japanese cars or U.S. television sets) on a four-item, 7-point (where $1=$ most negative and $7=$ most positive) semantic differential scale bound by the following polar adjectives: negative/ positive, dislike/like, bad/good, and undesirable/desirable. The reliabilities ranged from .91 to .97 .

Attitude toward the counterattitudinal attack. The attitude toward counterattitudinal attacks was assessed via a six-item semantic differential scale bound by the following polar adjectives: foolish/wise, unacceptable/acceptable, wrong/right, unfavorable/favorable, bad/good, and negative/positive. This scale was specifically developed for usage in resistance studies by Burgoon et al. (1978). The reliability was .95 .

Counterarguing output. Counterarguing is the second element in the original inoculation theory (McGuire, 1961a). To measure the level of counterarguing output, the recognition check-off procedure introduced in previous studies was used (see Pfau et al., 2005). Counterarguing output was structured as a sum of all arguments and counterarguments pertaining to the positive $\mathrm{COO}$ image checked by individuals on the check-off-recognition measure. 
Table 1

Descriptive Statistics of Covariate, Manipulation Check, and Dependent Variables

\begin{tabular}{lrrr}
\hline & \multicolumn{3}{c}{ Descriptive Statistics } \\
\cline { 2 - 4 } Variables & $M$ & $S D$ & $n$ \\
\hline Covariates & & & \\
$\quad$ Initial (Phase 1) attitude towards COO image & 5.74 & 1.04 & 433 \\
$\quad$ Involvement & 6.06 & 1.18 & 433 \\
$\quad$ COO importance & 4.78 & 1.60 & 433 \\
Manipulation check & & & \\
$\quad$ Threat & 3.87 & 1.36 & 433 \\
Dependent variables & & & \\
$\quad$ (Phase 3) Attitude toward the COO image & 5.28 & 1.17 & 399 \\
$\quad$ (Phase 3) Attitude toward the counterattitudinal attack & 3.31 & 1.38 & 400 \\
$\quad$ Phase 3) Counterarguing output & 13.68 & 7.36 & 422 \\
$\quad$ (Phase 4) Attitude toward the COO image & 4.93 & 1.36 & 386 \\
$\quad$ Phase 4) Attitude toward the counterattitudinal attack & 3.46 & 1.40 & 386 \\
$\quad$ (Phase 4) Counterarguing output & 12.24 & 7.13 & 387 \\
\hline
\end{tabular}

Note: Involvement, $\mathrm{COO}$ importance, and threat were measured using 1-7-interval scales. Higher values signify greater involvement, $\mathrm{COO}$ importance, and threat. Phase 1, Phase 3 , and Phase 4 attitudes toward the $\mathrm{COO}$ image were measured using 1-7-point scales. Higher numbers indicate more positive image and greater resistance to attacks. Phase 3 and Phase 4 counterarguing outputs were derived by combining the proattitudinal and counterattitudinal output. Higher numbers depict greater ability to counterargue, which leads to greater resistance to persuasion. Phase 3 and Phase 4 attitudes toward the attack were measured using 1-7-interval scales. Lower numbers indicate greater resistance to attacks.

To ensure the dependent variables provide convergence rather than redundancy, a Pearson's correlation test was performed on the three variables. The highest correlation between any two variables was $r=.26$, indicating independence among the three dependent variables.

The descriptive statistics for all of the covariates, manipulation checks, and dependent variables are contained in Table 1.

\section{Results}

\section{Statistical Analyses}

The statistical analysis employed a $4 \times 4 \times 2$ MANCOVA intended to determine the impact of product type/country conditions (cars made in Japan or the United States and television sets made in Japan or the United States), experimental condition (refutational, supportive, restoration, and control), and type of second attack (same and different) on the dependent variables. The purpose of this test was to 
Table 2

Omnibus Results -4 (Product Type/Country Condition) $\times 4$ (Message Strategy Condition) $\times 2$ (Nature of Second Attack) MANCOVA

\begin{tabular}{lcccc}
\hline Main and Interaction Effects & $F$ & $d f$ & $p$ & $\eta^{2}$ \\
\hline Covariates & & & & \\
$\quad$ Phase 1 attitude_COO image & 4.89 & $(4,341)$ & $*$ & .05 \\
$\quad$ Phase 1 COO importance & 4.24 & $(4,341)$ & $*$ & .05 \\
$\quad$ Phase 1 product involvement & 1.46 & $(4,341)$ & .21 & $n s$ \\
Independent variables main effects & & & & \\
$\quad$ Product/country manipulation & 1.26 & $(12,1029)$ & .24 & $n s$ \\
$\quad$ Message strategy condition & 18.08 & $(12,1029)$ & $*$ & .17 \\
$\quad$ Nature (content) of second attack & 1.73 & $(4,341)$ & .14 & $n s$ \\
Independent variables interaction effects & & & & \\
$1 \times 2$ & 0.80 & $(36,1376)$ & .80 & $n s$ \\
$1 \times 3$ & 0.99 & $(12,1029)$ & .46 & $n s$ \\
$2 \times 3$ & 1.21 & $(12,1029)$ & .27 & $n s$ \\
$1 \times 2 \times 3$ & 1.17 & $(36,1376)$ & .23 & $n s$ \\
\hline
\end{tabular}

Note: Asterisk depicts statistical significance at $p<.01 . n s$ indicates effect sizes were not calculated for statistically insignificant results.

examine the main effects of the experimental condition and type of second attack, as well as possible interaction effects between the experimental condition, the product type/country conditions, and the second attack in regard to the dependent variables. The COO importance, the initial (Phase 1) attitude toward the COO image, and the product involvement were included as covariates in this analysis to control for their influence on the dependent variables.

All of the omnibus results were followed by univariate tests and, where significant results were found, planned comparisons using Dunn's multiple comparison procedure (see Kirk, 1995) were computed on the predicted outcomes. Unpredicted outcomes, stemming from the research questions posited in this investigation, were assessed using Sheffe's post hoc tests, which are considered to be the most conservative (Hair, Anderson, Tatham, \& Black, 1995).

\section{Omnibus Multivariate Results}

The omnibus test of the $4 \times 4 \times 2$ MANCOVA revealed main effects for initial attitude toward the $\mathrm{COO}$ image and $\mathrm{COO}$ importance but not product involvement (for all omnibus results, see Table 2). The univariate tests for initial attitude toward the COO image indicated a significant effect on the dependent measure of Phase 4 attitude toward the COO image, whereas the univariate tests for the COO importance indicated significant effects on the dependent measure of Phase 4 attitude toward the attack and Phase 2 threat (for all univariate results, see Table 3 ).

The omnibus test did not reveal any significant main effects for the product type/ country conditions or the nature of the second attack. It did, however, reveal a main 
Table 3

Univariate Results-4 (Product Type/Country Condition) $\times 4$ (Message Strategy Condition) $\times 2$ (Nature of Second Attack) MANCOVA

\begin{tabular}{lccr}
\hline Covariates and Independent Variables & $F$ & $d f$ & $\eta^{2}$ \\
\hline $\begin{array}{l}\text { Dependent variables } \\
\text { Phase 1 attitude_COO image }\end{array}$ & & & \\
$\quad$ Phase 4 attitude_COO image & 18.08 & $(1,341)$ & .05 \\
Phase 1 COO importance & & & $.1,341)$ \\
$\quad$ Phase 4 attitude toward the attack & 5.84 & $(1,341)$ & .02 \\
$\quad$ Phase 2 threat & 8.42 & $(3,341)$ & .22 \\
Message (experimental) strategy condition & 32.16 & $(3,341)$ & .09 \\
$\quad$ Phase 4 attitude -COO image & 11.92 & $(3,341)$ & .14 \\
$\quad$ Phase 4 counterarguing output & 18.00 & $(3,341)$ & .25 \\
$\quad$ Phase 4 attitude toward the attack & 37.52 &
\end{tabular}

Note: Univariate tests were conducted only on the variables that were flagged as statistically significant by the omnibus test. All of the univariate results presented in the table are statistically significant at $p<.01$.

effect for experimental condition with univariate tests indicating significant effects on the dependent measures of Phase 2 threat, Phase 4 attitude toward the COO image, Phase 4 number of counterarguing output, and Phase 4 attitude toward the attack. The omnibus test did not reveal any two- or three-way interactions; thus, the two product types (cars and television sets) and two country conditions (Japan and the United States) were combined.

\section{Hypothesis Addressing the Nature of the Second Attack}

Hypothesis 1 addressed issues related to the nature of the second attack. This hypothesis is presented first due to the consequence of the results of Hypotheses 1 for the remainder of the analyses. More specifically, should Hypothesis 1 be supported, then the nature of the attack can be ignored in subsequent analyses, but should Hypothesis 1 fail to be supported, then the nature of attack would need to be taken into consideration in subsequent analyses.

Hypothesis 1 proposed that inoculation would work equally well regardless of the nature of the second attack. As the hypothesis of interest was the null, an initial test of statistical power was first conducted to ensure that the sample size used in the subsequent analysis was sufficient to detect possible group differences. Relying on commonly accepted measurement standards for power analysis $(\alpha=.95,1-\beta=.80$; Cohen, 1990) and an estimated effect size of $r=.20$, which is the average effect size of inoculation studies (see meta-analysis by Banas \& Rains, 2008), a sample size of 153 participants should be sufficient to generate enough power to detect possible differences. Since the required sample size was well within the actual sample size collected, analysis of Hypothesis 1 proceeded. 
The omnibus test did not discover main effect or interaction effects for the nature of the second attack (see Table 2), thus confirming Hypothesis 1. Consequently, the nature of the second attack was ignored in subsequent analyses.

\section{Research Question Addressing the Robustness of Inoculation Over Time With Multiple Attacks}

Research Question 1 asked whether attitudes and counterarguing ability of inoculated individuals strengthens, weakens, or remains unchanged in the face of repeated attacks. In order to answer this question, a series of repeated measure ANOVA tests were conducted on each of the three dependent variables: the ability of individuals to generate counterarguing output, the attitude toward the attack message, and the attitude toward the COO image. Within-subjects effects were computed with the Greenhouse-Geisser adjustment, which corrects sphericity problems. The omnibus results of the repeated subjects ANOVAs, with Greenhouse-Geisser corrections, revealed significant differences between Phase 3 and Phase 4 attitude toward the COO image, $F(1,181)=10.93, p<.01, \eta^{2}=.02$, and level of counterarguing output, $F(1,201)=13.85, p<.01, \eta^{2}=.01$. An examination of the patterns of means revealed a slight, but statistically significant, decline in the effectiveness of the inoculation treatment to protect attitude toward $\mathrm{COO}$ image. A similar pattern is observed with the ability of individuals to generate counterarguing output. No significant differences were uncovered between Phase 3 and Phase 4 attitude toward the message attack, $F(1,181)=1.38, p=.24$ (for sample sizes, means, and standard deviations, please refer to Table 4).

\section{Research Question Addressing the Effectiveness of Resistance Strategies in the Face of Multiple Attacks}

Research Question 2 addressed the effectiveness of each strategy in the face of multiple attacks. The omnibus test discovered a main effect for experimental condition, and more specifically, significant effects on the dependent measures of Phase 4 attitude toward the COO image, Phase 4 number of counterarguing output, and Phase 4 attitude toward the attack. Mean comparisons of unpredicted outcomes were conducted using Sheffe's post hoc test (for sample sizes, means, and standard deviations, please refer to Table 5).

The results indicated that, after facing multiple attacks, compared to control, individuals receiving restoration, supportive, or refutational messages were able to generate more counterarguments, had more negative attitude toward the attack message, and displayed a stronger attitude toward COO image (for post hoc test results, see Table 6). Equivalent outcome was observed when refutational messages were compared to restoration or supportive messages. The results showed refutational messages to generate greater resistance to multiple attacks compared to all other 
Table 4

\section{Comparison of the Effectiveness of Refutational Treatments in the Face of Multiple Attacks}

\begin{tabular}{lcc}
\hline & \multicolumn{2}{c}{ Refutational Treatment Condition } \\
\cline { 2 - 3 } Dependent Measure & Phase 3 & Phase 4 \\
\hline COO image & $5.73^{\mathrm{a}}(0.97)$ & $5.46^{\mathrm{a}}(1.19)$ \\
$M(S D)$ & 182 & 182 \\
$\quad n$ & $15.97^{\mathrm{a}}(7.31)$ & $14.40^{\mathrm{a}}(7.48)$ \\
Counterarguing output & 202 & 202 \\
$M(S D)$ & & $3.09(1.36)$ \\
$n$ & $2.97(1.41)$ & 182 \\
Attitude toward the attack & 182 & \\
$M(S D)$ & &
\end{tabular}

Note: Phase 3 and Phase 4 attitudes toward the COO image were measured on 1-7-interval scales. Higher numbers signify more positive image and greater resistance to attacks. Phase 3 and Phase 4 counterarguing outputs were derived by combining the proattitudinal and counterattitudinal output. Higher numbers depict greater ability to counterargue, which leads to greater resistance to persuasion. Phase 3 and Phase 4 attitudes toward the attack were measured using 1-7-point scales, with lower numbers indicating greater resistance to attacks.

a. Statistically significant groups at $p<.05$.

Table 5

Comparison of the Effectiveness of Different Resistance Strategies in the Face of Multiple Attacks

\begin{tabular}{lcccc}
\hline & \multicolumn{4}{c}{ Message (Experimental) Conditions } \\
\cline { 2 - 5 } & $\begin{array}{c}\text { Control } \\
(n=43)\end{array}$ & $\begin{array}{c}\text { Restoration } \\
(n=65)\end{array}$ & $\begin{array}{c}\text { Supportive } \\
(n=58)\end{array}$ & $\begin{array}{c}\text { Refutational } \\
(n=173)\end{array}$ \\
\hline $\begin{array}{l}\text { Pependent Measure } \\
\quad M\end{array}$ & $3.38^{\mathrm{ab}}$ & $4.81^{\mathrm{a}}$ & $4.81^{\mathrm{b}}$ & $5.37^{\mathrm{ab}}$ \\
$\quad(S D)$ & $(1.05)$ & $(1.24)$ & $(1.14)$ & $(1.22)$ \\
Phase 4 counterarguing output & & & & \\
$\quad M$ & $8.07^{\mathrm{a}}$ & $12.64^{\mathrm{a}}$ & $9.77^{\mathrm{a}}$ & $14.23^{\mathrm{a}}$ \\
$\quad(S D)$ & $(4.67)$ & $(6.25)$ & $(4.83)$ & $(7.56)$ \\
Phase 4 attitude towards the attack & & & & \\
$\quad M$ & $4.72^{\mathrm{a}}$ & $3.41^{\mathrm{a}}$ & $4.03^{\mathrm{a}}$ & $3.07^{\mathrm{a}}$ \\
$(S D)$ & $(1.42)$ & $(1.27)$ & $(1.03)$ & $(1.35)$ \\
\hline
\end{tabular}

Note: Phase 4 attitude towards the COO image was measured using 1-7-interval scales. Higher numbers indicate more positive image and greater resistance to attacks. Phase 4 counterarguing output was derived by combining the pro-attitudinal and counter-attitudinal output. Higher numbers depict greater ability to counterargue, which leads to greater resistance to persuasion. Phase 4 attitude towards the attack was measured using 1-7-point scales, with lower numbers indicating greater resistance to attacks.

ab. Depict statistically significant groups at $p<.05$. 
Table 6

Research Question 2 Post Hoc Results-4

(Product Type/Country Condition) $\times 4$ (Message Strategy

Condition) $\times 2$ (Nature of Second Attack) MANCOVA

\begin{tabular}{|c|c|c|c|c|c|c|}
\hline \multirow[b]{2}{*}{ Dependent Variables } & \multicolumn{6}{|c|}{ Message (Experiment) Conditions Compared } \\
\hline & $t$ & $d f$ & $\eta^{2}$ & $t$ & $d f$ & $\eta^{2}$ \\
\hline & \multicolumn{3}{|c|}{ Control vs. Restoration } & \multicolumn{3}{|c|}{ Restoration vs. Supportive } \\
\hline Phase 4 attitude - COO image & 13.21 & 106 & .62 & & & \\
\hline Phase 4 attitude toward the attack & 10.33 & 106 & .50 & 5.38 & 121 & .19 \\
\hline \multirow[t]{2}{*}{ Phase 4 counterarguing output } & 7.33 & 106 & .34 & 4.91 & 121 & .17 \\
\hline & \multicolumn{3}{|c|}{ Control vs. Supportive } & \multicolumn{3}{|c|}{ Supportive vs. Refutation } \\
\hline Phase 4 attitude - COO image & 12.79 & 99 & .62 & 7.57 & 232 & .20 \\
\hline Phase 4 attitude toward the attack & 5.45 & 99 & .23 & 11.43 & 232 & .36 \\
\hline \multirow[t]{2}{*}{ Phase 4 counterarguing output } & 7.64 & 99 & .37 & 10.35 & 232 & .32 \\
\hline & \multicolumn{3}{|c|}{ Control vs. Refutation } & \multicolumn{3}{|c|}{ Restoration vs. Refutation } \\
\hline Phase 4 attitude - COO image & 26.03 & 217 & .76 & 7.68 & 239 & .20 \\
\hline Phase 4 attitude toward the attack & 19.01 & 217 & .62 & 4.11 & 239 & .07 \\
\hline Phase 4 counterarguing output & 13.83 & 217 & .47 & 3.75 & 239 & .06 \\
\hline
\end{tabular}

Note: The above table presents the post hoc tests indicating statistically significant results on Research Question 2. Nonsignificant tests were omitted. All of the post hoc results presented in the table are statistically significant at $p<.01$.

strategies presented in this investigation. No difference was found in the effectiveness of restoration and supportive messages to protect the attitude toward the COO image; however, individuals receiving restoration messages, as opposed to supportive ones, had more negative attitude toward the attack message and were able to generate greater counterarguing output.

\section{Discussion}

Previous research has positioned inoculation as a viable preemptive strategy, with capabilities of protecting consumer attitudes in the marketplace from competitor attacks, thus confirming Bither, Dolich, and Nell's (1971) conclusion that inoculation should protect against competitor's attacks. Inoculation's refutational messages are better able to protect attitudes than supportive strategies, restoration strategies, or no strategy at all (Ivanov et al., 2009). Previous research has tested the effectiveness of inoculation against single attacks. As argued, this approach is uncommon in the field of advertising and in most interpersonal and mass media contexts. It is more likely to 
expect that attitudes will be subjected to multiple attacks by competitors. The attacks may carry an identical message or a variation of a theme. So, how would inoculation, as well as the other strategies, fare in the face of multiple attacks? In addition, will the nature of the attack (same or different) impact the effectiveness of the strategy?

Based on the results generated by this investigation, it seems that the effectiveness of the refutational messages somewhat dissipates when faced with a subsequent attack. This result is congruent with, and may provide further support to, the belief that induced motivation (Insko, 1967) decays over time. The competing belief, introduced in this investigation, proposed that each subsequent attack may act as a booster and, thus, provide additional motivation for individuals to shore up their defenses. However, this reasoning was not directly supported by the results of current investigation. Still, it may be premature to reject outright the idea that subsequent attacks may boost the individuals' motivation to shore up attitudes. It may well be that the first attack acts as a booster, thus preventing more pronounced motivation decay, resulting in a greater attitude shift. The current investigation used a design in which each participant was subjected to each attack. A future design should subject some of the participants to all attacks, whereas other participants only to subsequent, and not initial, attacks in order to determine the impact of the initial attack. In addition, future studies should use more than two attacks to provide a better understanding and insight into the workings and effectiveness of refutational messages.

Even though the effectiveness of the refutational messages somewhat dissipates with time, the results of this investigation provided evidence for the superiority of inoculation in comparison to other strategies in conferring resistance to persuasive attacks. Images of brands, products, countries, and corporations may be expected to deteriorate over time, as the success of inoculation may be somewhat limited. Still, the findings of this investigation highlight the ability of inoculation to protect attitudes over time and in the face of multiple attacks. Inoculation fared better than any other strategy employed in this investigation.

This study, although preliminary, attests to the robust nature of inoculation. Never before has the effectiveness of inoculation been tested in the face of multiple attacks. The failure to feature multiple attacks in previous studies is a shortcoming in inoculation research. In practice, people are unlikely to face only one attack, regardless of the nature of the attitude held. Whether inoculation is used in an interpersonal context (e.g., protecting the negative attitude toward smoking against peer pressure) or mass media context (e.g., protecting the brand, product, corporate, or COO image against competitors' advertising attacks), the number of attacks encountered is likely to be more than one. A teenager is likely to face constant and repeated pressure from his or her peers to succumb to smoking. At the same time, a consumer is likely to face a barrage of attacks orchestrated by competitors aimed at the consumer's choice of brand (or product) or attempting to tarnish the positive corporate (or COO) image. The same can be said about a voter receiving a barrage of mass media or interpersonal messages derogating the position or character of a political candidate. Yet the success of the theory had not been assessed in the face of multiple attacks until now. Thus, 
this study is pioneer in assessing the strength of inoculation when facing multiple attacks. The results indicate that inoculation is capable of arming individuals with defenses to withstand repeated pressures from peers or competitors. This finding renders the theory both practical and useful, thus extending its utility and importance.

Future efforts should further test the effectiveness of inoculation with multiple attacks in order to determine how many attacks it would take to completely dissipate the effects of inoculation, if such a number exists. In addition, if multiple attacks over time minimize effects of inoculation, should this finding be attributed to the multiple attacks, the inoculation message and motivation decay over time, or some combination of the two?

In addition to the effectiveness of refutational messages in the face of multiple attacks, it seems that the nature of the additional attacks, whether using the same message or a barrage of related messages, would have little impact on the effectiveness of the inoculation strategy. This predicted finding provides further support for McGuire's (1961a) belief that the motivation, and not necessarily the specific message content, is responsible for the effectiveness of inoculation. This finding is also confirmed by a recent meta-analysis of inoculation studies which found no differences in the effectiveness of refutational same and different inoculation treatments (Banas \& Rains, 2008). It is important to note that the consistent findings in inoculation research stand in contrast to expectations of the dual processing theories (see Petty \& Cacioppo, 1986) and the functional theory of attitudes (see Katz, 1960), which predict that the combination of motivation and message content would provide the most pronounced attitude change. Inoculation findings seem to suggest that the role of message content in resistance is minor and perhaps negligible.

Counterarguing is one of the major elements of inoculation theory. This variable is "presumed to be subvocal, psychological process. As such, direct observation of the variable becomes extremely difficult, if not impossible" (Brandt, 1979, p. 324). Over the years, a superior strategy has not emerged to overcome this measurement difficulty. The check-off-recognition method, originated by Miller and Baron (1973) and used in this study to test the level of counterarguing output, was only recently introduced to the inoculation literature (e.g., Pfau, Compton, Parker, An et al., 2006; Pfau et al., 2004, 2005). Although successful in each application including the current one, it diverges from the traditional and widely accepted method of thought listing (e.g., Pfau, 1992, 1997). Regrettably, both (check-off recognition and thought listing) methods, although sufficient, are limited in their ability to effectively tap the subvocal psychological process of counterarguing. Future studies should continue to search for a better method to operationalize this variable.

Overall, the findings of this investigation are important. They offer the basis for better understanding of the workings of inoculation theory in more natural settings where the attitudes of people are constantly challenged, rather than the less natural experimental settings where the attitude challenge occurs only once. This investigation should provide the impetus for more research to nuance the workings of inoculation theory in the face of multiple attacks. 


\section{Notes}

1. Please address all correspondence to Bobi Ivanov, Assistant Professor, School of Journalism \& Telecommunications, University of Kentucky, 137 Grehan Building, Lexington, KY; e-mail: bobi. ivanov@uky.edu.

2. In the current investigation, all of the inoculation message approaches were effective in conferring resistance. Potential differences in the effectiveness of varied message types, cognitive and affective, have been discussed elsewhere (see Ivanov et al., 2009; Pfau et al., 2001). The purpose of this study was to examine inoculation's effectiveness against multiple attacks, rather than to explore differences in message types.

\section{References}

Arndorfer, J. B. (2004, August 23). Miller turnaround hits one-year mark for surging Lite line. Advertising Age, p. 6.

Arndorfer, J. B. (2005, March 28). If you love your country, drink Bud. Advertising Age, p. 1, 22.

Atkin, C. K. (1984). Consumer and social effects of advertising. In B. Dervin \& M. J. Voigt (Eds.), Progress in communication sciences (Vol. 4, pp. 205-248). Norwood, NJ: Ablex.

Atkinson, C. (2007, September 4). Drivers size up Ford (unknowingly) in new campaign. The New York Times, p. C3.

Banas, J. A., \& Rains, S. A. (2008, November). A meta-analysis of research on inoculation theory. Paper presented at the annual meeting of the National Communication Association, San Diego, CA.

Becker, S. W., Bavelas, A., \& Braden, M. (1961). An index to measure contingency of English sentences. Language and Speech, 4, 138-145.

Belch, G. E., \& Belch, M. A. (2007). Advertising and promotion: An integrated marketing communications perspective. New York: McGraw-Hill.

Bither, S. W., Dolich, I. J., \& Nell, E. B. (1971). The application of attitude immunization techniques in marketing. Journal of Marketing Research, 18, 56-61.

Boddewyn, J. J., \& Marton, K. (1978). Comparison advertising: A worldwide study. New York: Hastings House.

Brandt, D. R. (1979). Listener propensity to counterargue, distraction, and resistance to persuasion. Central States Speech Journal, 30, 321-331.

Burgoon, M., Cohen, M., Miller, M. D., \& Montgomery, C. L. (1978). An empirical test of a model of resistance to persuasion. Human Communication Research, 5, 27-39.

Burgoon, M., Pfau, M., \& Birk, T. S. (1995). An inoculation theory explanation for the effects of corporate issue/advocacy advertising campaigns. Communication Research, 22, 485-505.

Carter, A. (2005, March 28). Making lite of the king. BusinessWeek, p. 105.

Chao, P. (1993). Partitioning country of origin effects: Consumer evaluations of hybrid products. Journal of International Business Studies, 24, 291-306.

Cohen, J. (1990). Things I have learned (so far). American Psychologist, 45, 1304-1312.

Compton, J., \& Pfau, M. (2005). Inoculation theory of resistance to influence at maturity: Recent progress in theory development and application and suggestions for future research. In P. Kalbfleisch (Ed.), Communication yearbook 29 (pp. 97-145). Mahwah, NJ: Lawrence Erlbaum.

Cordell, V. V. (1991). Competitive context and price as moderators of country of origin preferences. Journal of the Academy of Marketing Science, 19, p. 123.

Dougherty, P. H. (1973, November 14). Advertising: Comparison issue. New York Times. 
Droge, C. (1989). Shaping the route to attitude change: Central versus peripheral processing through comparative versus noncomparative advertising. Journal of Marketing Research, 26, 193-204.

Hair, F. H., Jr., Anderson, R. E., Tatham, R. L., \& Black, W. C. (1995). Multivariate data analysis with readings (4th ed.). Englewood Cliffs, NJ: Prentice Hall.

Hawkins, D. I., Albaum, G., \& Best, R. (1977). An investigation of two issues in the use of students as surrogates for housewives in consumer behavior studies. Journal of Business, 50, 216-222.

Insko, C. A. (1967). Theories of attitude change. New York: Appleton-Century-Crofts.

Ivanov, B., Pfau, M. W., \& Parker, K. A. (2007, November). The potential of inoculation in promoting resistance to the effectiveness of multiple competitive attacks on the country of origin concept. Paper presented at the annual meeting of the American Marketing Association, San Diego, CA.

Ivanov, B., Pfau, M. W., \& Parker, K. A. (2009, March). The attitude base as a moderator of the effectiveness of inoculation strategy. Communication Monographs, 76, 47-72.

Johansson, J. K. (1992). Missing a strategic opportunity: Managers' denial of country-of-origin effects. In N. Papadopoulos \& L. A. Heslop (Eds.), Product-country images (pp. 77-86). Binghamton, NY: The Haworth Press.

Kardes, F. R. (2001). Consumer behavior and managerial decision making ( $2^{\text {nd }}$ ed.). Upper Saddle River, NJ: Pearson Education, Inc.

Katz, D. (1960). The functional approach to the study of attitudes. Public Opinion Quarterly, 24, 163-204.

Kirk, R. E. (1995). Experimental design: Procedures for behavioral sciences ( $3^{\text {rd }}$ ed.). Pacific Grove, CA: Brooks/Cole.

Lampert, S. I., \& Jaffe, E. D. (1998). A dynamic approach to country-of-origin effect. European Journal of Marketing, 32, 61-78.

Lampert, S. I., \& Jaffe, E. D. (1996). Country of origin effects on international market entry. Journal of Global Marketing, 10, 27-52.

Lee, W., \& Pfau, M. (1997). The effectiveness of cognitive and affective inoculation appeals in conferring resistance against cognitive and affective attacks. Paper presented at the annual meeting of the International Communication Association, Jerusalem, Israel.

Levy, R. (1987). Big resurgence in competitive ads. Dun's Business Month, 129, 56-58.

Liefeld, J. P. (1992). Experiments on country-of-origin effects: Review and meta-analysis of effect size. In N. Papadopoulos \& L. A. Heslop (Eds.), Product-country images (pp. 117-156). Binghamton, NY: The Haworth Press, Inc.

MacArthur, K. (2007, May 22). Why big brands are getting into the ring. Retrieved October 29, 2008, from http://adage.com/article?article_id=116722\&search_phrase=Why+big + brands + are + getting + into+ the+ring

Mazzocco, P. J. (2000). Mental imagery and the attitude change process. , Unpublished master's thesis, The Ohio State University, Columbus.

Mazzocco, P. J., \& Brock, C. B. (2006). Understanding the role of mental imagery in persuasion: A cognitive resources model analysis. In L. R. Kahle \& C. H. Kim (Eds.), Creating images and the psychology of marketing communication (pp. 65-78). Mahwah, NJ: Erlbaum.

McGuire, W. J. (1961a). The effectiveness of supportive and refutational defenses in immunizing and restoring beliefs against persuasion. Sociometry, 24, 184-197.

McGuire, W. J. (1961b). Resistance to persuasion conferred by active and passive prior refutation of same and alternative counterarguments. Journal of Abnormal Psychology, 63, 326-332.

McGuire, W. J. (1962). Persistence of the resistance to persuasion induced by various types of prior belief defenses. Journal of Abnormal and Social Psychology, 64, 241-248.

McGuire, W. J. (1964). Inducing resistance to persuasion: Some contemporary approaches. In L. Berkowitz (Ed.), Advances in experimental social psychology (Vol. 1, pp. 191-229). New York: Academic Press.

McGuire, W. J. (1966). Persistence of the resistance to persuasion induced by various types of prior belief defenses. In C. W. Backman \& P. P. Secord (Eds.), Problems in social psychology (pp. 128-135). New York: McGraw-Hill. 
McGuire, W. J., \& Papageorgis, D. (1961). The relative efficacy of various types of prior belief-defense in producing immunity against persuasion. Journal of Abnormal Psychology, 62, 327-337.

Miller, W. B., \& Baron, R. S. (1973). On measuring counterarguing. Journal for the Theory of Social Behavior, 1, 101-118.

Mitchell, S. (2004, June 6). Brewing giants go head to head in court. The Post.IE: The Sunday Business Post Online. Retrieved September 21, 2005, from http:/archives.tcm.ie/businesspost/2004/06/06/ story734655334.asp\#

Mohamad, O., Ahmed, Z. U., Honeycutt, E. D., \& Tyebkhan, T. H. (2000, Fall). Does “made in . . ." matter to consumers? A Malaysian study of country of origin effect. Multinational Business Review, 73.

Morello, G. (1992). International product competitiveness and the "made in" concept. In N. Papadopoulos \& L. A. Heslop (Eds.), Product-country images (pp. 285-309). Binghamton, NY: The Haworth Press.

Nabi, R. L. (2003). "Feeling" resistance: Exploring the role of emotionally evocative visuals in inducing inoculation. Media Psychology, 5, 199-223.

Papageorgis, D., \& McGuire, W. J. (1961). The generality of immunity to persuasion produced by preexposure to weakened counterarguments. Journal of Abnormal Psychology, 62, 475-481.

Petty, R., \& Cacioppo, J. (1986). The elaboration likelihood model of persuasion. Advances in Experimental Social Psychology, 19, 123-205.

Pfau, M. (1991, November). Impact of product involvement, message format, and receiver gender on the efficacy of comparative advertising messages. Paper presented at the annual meeting of the Speech Communication Association, Atlanta, GA.

Pfau, M. (1992). The potential of inoculation in promoting resistance to the effectiveness of comparative advertising messages. Communication Quarterly, 40, 26-44.

Pfau, M. (1997). The inoculation model of resistance to influence. In F. J. Boster \& G. Barnett (Eds.), Progress in communication sciences (Vol. 13, pp. 133-171). Norwood, NJ: Ablex.

Pfau, M., \& Burgoon, M. (1988). Inoculation in political campaign communication. Human Communication Research, 15, 91-111.

Pfau, M., Compton, J., Parker, K. A., An, C., Wittenberg, E. M., Ferguson, M., Horton, H., \& Malyshev, Y. (2006). The conundrum of the timing of counterarguing effects in resistance: Strategies to boost the persistence of counterarguing output. Communication Quarterly, 54, 143-156.

Pfau, M., Compton, J., Parker, K. A., Wittenberg, E. M., An, C., Ferguson, M., et al. (2004). The traditional explanation for resistance based on the core elements of threat and counterarguing and an alternative rationale based on attitude accessibility: Do these mechanisms trigger distinct or overlapping process of resistance? Human Communication Research, 30, 329-360.

Pfau, M., Ivanov, B., Houston, B., Haigh, M., Sims, J., Gilchrist, E., et al. (2005). Inoculation and mental processing: The instrumental role of associative networks in the process of resistance to counterattitudinal influence. Communication Monographs, 72, 414-441.

Pfau, M., Kenski, H. C., Nitz, M., \& Sorenson, J. (1990). Efficacy of inoculation strategies in promoting resistance to political attack messages: Application to direct mail. Communication Monographs, 57, 25-43.

Pfau, M., Roskos-Ewoldsen, D., Wood, M., Yin, S., Cho, J., Lu, K. H., et al. (2003). Attitude accessibility as an alternative explanation for how inoculation confers resistance. Communication Monographs, $70,39-51$.

Pfau, M., Szabo, E. A., Anderson, J., Morrill, J., Zubric, J., \& Wan, H. H. (2001). The role and impact of affect in the process of resistance to persuasion. Human Communication Research, 27, 216-252.

Pfau, M., \& Van Bockern, S. (1994). The persistence of inoculation in conferring resistance to smoking initiation among adolescents: The second year. Human Communication Research, 20, 413-430.

Pride, W. M., Lamb, C. W., \& Pletcher, B. A. (1979). The informativeness of comparative advertisements: An empirical investigation. Journal of Advertising, 8, 29-48. 
Pryor, B., \& Steinfatt, T. M. (1978). The effects of initial belief level on inoculation theory and its proposed mechanisms. Human Communication Research, 4, 217-230.

Roth, M. S., \& Romeo, J. B. (1992). Matching product category and country image perceptions: A framework for managing country-of-origin effects. Journal of International Business Studies, 23, 477-497.

Snyder Bulik, B. (2007, February 12). Apple plan: Lead consumers into temptation-and away from Vista. Advertising Age, p. 1, 28.

Sorescu, A. B., \& Gelb, B. D. (2000). Negative comparative advertising: Evidence favoring fine-tuning. Journal of Advertising, 29, 25-40.

Tannenbaum, P. H., Macauley, J. R., \& Norris, E. L. (1966). Principle of congruity and reduction of persuasion. Journal of Personality and Social Psychology, 3, 233-238.

Ulanoff, S. M. (1975, February). Comparison advertising: An historical perspective (pp. 9-46). Cambridge, MA: Marketing Science Institute Working Paper.

Yavas, U. (1994). Research note. International Marketing Review, 11, 35-43.

Zaichkowsky, J. L. (1985). Measuring the involvement construct. Journal of Consumer Research, 12, 341-352.

Bobi Ivanov, PhD (University of Oklahoma) is assistant professor at the School of Journalism \& Telecommunications, University of Kentucky. His research interests concern the influence of mass media communication, message processing, and resistance to influence, particularly the uses of inoculation. He has coauthored journal articles appearing in Communication Monographs and Central Business Review and a book titled Adolescents and Communication Regarding Sex and Contraception: Examining Adolescent Communication (2008, VDM Verlag: Saarbrucken, Germany). His coauthored Communication Monographs article titled "Inoculation and Mental Processing: The Instrumental Role of Associative Networks in the Process of Resistance to Counterattitudinal Influence" won the National Communication Association Communication Social Cognition Division's Distinguished Article Award. He is also a recipient of the University of Oklahoma, Department of Communication's H. Wayland Cummings Best Quantitative Dissertation Award.

Michael Pfau, $\mathrm{PhD}$ (University of Arizona), is professor and chair at the Department of Communication, University of Oklahoma. His research interests concern the influence of mass media communication and resistance to influence, particularly the uses of inoculation. He has coauthored and/or edited seven books. The most recent include, Mediating the Vote: The Changing Media Landscape in U.S. Presidential Campaigns (2007, Rowman and Littlefield) and The Handbook of Persuasion: Theory and Practice (2002, Sage). He has authored or coauthored more than 100 journal articles and book chapters. His publications have won the NCA Communication and Social Cognition Division's Distinguished Book Award and Distinguished Article Award, and NCA's Golden Anniversary Monographs Award.

Kimberly A. Parker, PhD (University of Oklahoma) is assistant professor at the Department of Communication, Bellarmine University, Louisville, Kentucky. Her research interests concern message processing, resistance to influence, and adolescent romantic and sexual communication. She has coauthored journal articles appearing in Human Communication Research, Communication Monographs, Communication Quarterly, Communication Studies, and Central Business Review and a book titled Adolescents and Communication Regarding Sex and Contraception: Examining Adolescent Communication (2008, VDM Verlag: Saarbrucken, Germany).

For reprints and permissions queries, please visit SAGE's Web site at http://www.sagepub .com/journals Permissions.nav. 